\title{
LOS MÉDICOS DE LA CAMPAÑA NACIONAL DE 1856-1857
}

\author{
Doctors of the National Campaign of 1856-1857 \\ Luko Hilje Quirós \\ Centro Agronómico Tropical de Investigación y Enseñanza (CATIE), Costa Rica
}

luko@ice.co.cr

Recibido: 29-03-2021

Aprobado: 01-05-2021

Luko Hilje Quirós es Licenciado en Biología y doctor en Entomología, miembro de la Asamblea de Fundadores del Instituto Nacional de Biodiversidad (INBio) y miembro honorario del Colegio de Ingenieros Agrónomos de Costa Rica. Es Profesor Emérito del Centro Agronómico Tropical de Investigación y Enseñanza (CATIE), Turrialba, Costa Rica.

Walker, Karl Hoffmann, Costa Rica.

\section{RESUMEN}

En la Campaña Nacional de 1856-1857 contra el ejército filibustero comandado por William Walker, la salud de las tropas costarricenses estuvo a cargo de unos doce médicos, en diferentes momentos. Encabezados por el alemán Karl Hoffmann durante la primera etapa de la Campaña, los hubo tanto nacionales (Cruz Alvarado Velazco, Andrés Sáenz Llorente, Bernabé Bermúdez, Manuel María Esquivel y Bruno Carranza) como extranjeros (Santiago Hogan, Fermín Meza Orellana, Francisco Bastos, Franz Ellendorf, Alexander von Frantzius y Marquis L. Hine). Este artículo brinda una visión sintética, unificada y actualizada de la manera en que el gobierno costarricense respondió a la crisis sanitaria, así como de los aportes particulares de cada uno de los médicos y sus ayudantes de enfermería en la atención de los combatientes heridos y frente a la epidemia del cólera.

Palabras clave: Guerra, salud, cólera morbus, filibusterismo, William

\section{ABSTRACT}

In the National Campaign of 1856-1857 against the filibuster army commanded by William Walker, some twelve doctors were in charge of the health of the Costa Rican troops, at different times. Led by the German Karl Hoffmann during the first stage of the Campaign, the group included both national (Cruz Alvarado Velazco, Andrés Sáenz Llorente, Bernabé Bermúdez, Manuel María Esquivel, and Bruno Carranza) and foreign physicians (Santiago Hogan, Fermín Meza Orellana, Francisco Bastos, Franz Ellendorf, Alexander von Frantzius, and Marquis L. Hine). This article provides a synthetic, unified and updated vision of the way in which the Costa Rican government responded to the sanitary crisis, as well as the particular contributions of each of the doctors and their nursing assistants in the care of the injured soldiers and in the face of the cholera epidemics.

Keywords: War, health, filibusterism, cholera morbus, William Walker, Karl Hoffmann, Costa Rica. 
Revista Herencia, Vol. 34 (2), enero-junio, 2021.

\section{Introducción}

A diferencia de muchas naciones latinoamericanas, cuyas luchas por la independencia de España fueron muy prolongadas y cruentas, la de los países centroamericanos - concretada el 15 de setiembre de 1821- fue pacífica. Sin embargo, ese ahorro en vidas, sangre y dolor hubo que saldarlo 35 años después, cuando la soberanía y la identidad de dichos países estuvieron amenazadas por el ejército filibustero de William Walker, que contaba con el apoyo político, financiero y logístico de importantes personajes y sectores de los estados del sur de los EE.UU., partidarios de la esclavitud.

Por fortuna, ante tan grave situación, hubo profesionales en medicina y enfermería que supieron enfrentarse al desafío de salvar vidas, no solo de la pólvora, los sables y las bayonetas, sino que también de la epidemia del cólera morbus. No obstante, sus aportes aparecen dispersos en numerosas publicaciones, en algunas de las cuales se incurre en errores y confusiones acerca de su participación específica en los diferentes episodios de la Campaña Nacional de 1856-1857, así como sobre la naturaleza de esos aportes. Esto ha sido subsanado en parte gracias a libros relativamente recientes (Arias, 2002; Hilje, 2007a, 2013), pero en ellos tampoco es sencillo formarse una idea exacta de la composición ese grupo de médicos y enfermeros, ni de sus acciones particulares. Aunque Hilje (2007b) hizo un intento en tal sentido, se restringió a los médicos extranjeros; además, sobre algunos de éstos hoy se cuenta con nuevos datos, que se incluyen aquí.

Por tanto, el objetivo de este artículo es brindar una visión sintética, unificada y actualizada al respecto, lo cual resulta oportuno al conmemorarse este año el bicentenario de la independencia de Costa Rica, y así honrar su memoria. A su vez, esto ocurre cuando el mundo entero libra una incesante batalla ante el embate del coronavirus SARS-Cov-2, en la cual los profesionales de dicho ramo han demostrado una actitud quizás tan abnegada y ejemplar como la de hace dos siglos. 
Revista Herencia, Vol. 34 (2), enero-junio, 2021.

\section{El entorno médico de entonces}

Quizás la mejor fuente para conocer quiénes ejercían la medicina en la Costa Rica de la época aludida, es una crónica sobre la vida cotidiana en la capital, escrita por un singular testigo de excepción, el alemán Francisco (Chico) Rohrmoser von Chamier (Hilje, 2010).

En efecto, él acota que "los médicos eran los doctores Hoffmann (sin duda el A. № 1 entre todos), Ellendorf, Hartmann, Hogan (americano), José María Montealegre, Bruno Carranza, Cruz Alvarado, Toledo (padre de Nazario) y Chepe (?) Esquivel". Asimismo, al referirse a las farmacias, señala que "las boticas: de Juan Braun, pegada a Joaquín Mora; del doctor Hoffmann, pegada a Joy \& von Schröter, estaba manejada por un alemancito Ilamado Anteojitos; del doctor Carit, enseguida de Quirós \& Ellerbrock". Sus nombres completos aparecen posteriormente. Quizás porque no residían en la capital, o tal vez por olvido - pues Rohrmoser escribió sus recuerdos cuando frisaba los 83 años-, omitió a importantes doctores, a quienes se aludirá después.

Nótese que algunos médicos, como Hoffmann y Carit, instalaron boticas-consultorios para atender a sus pacientes. Estos competían con farmacéuticos profesionales, como el alemán Juan Braun u otros que no lo eran, como el también alemán Otto Emilio Loeper, dueño de la Botica de la Plaza.

Aunque San José era una ciudad minúscula y toda la gente se conocía, en cierto momento los médicos empezaron a ofrecer sus servicios profesionales por medio de la prensa. Al respecto, aunque el Boletín Oficial -que era el único periódico de entonces- empezó a incluir anuncios comerciales en febrero de 1855, como "alcances", los primeros avisos de boticas que hemos hallado datan de julio de 1858, pero en Crónica de Costa Rica, que 
Revista Herencia, Vol. 34 (2), enero-junio, 2021.

reemplazó a dicho boletín. Puesto que era necesario garantizar el acceso a medicinas a cualquier hora, el gobierno estableció la norma de que cada semana estuviera abierta apenas una botica; por ello, en la semana previa aparecía un pequeño recuadro en la prensa, en el que se indicaba la botica "de servicio" o "de turno" que estaría abierta.

Ahora bien, como en aquella época no existía la Universidad de Santo Tomás, no había dónde formar médicos en el país, por lo que debía recurrirse a la Universidad de San Carlos, en Guatemala. Al parecer, el primer costarricense graduado allá fue el cartaginés Pablo Alvarado Bonilla, a quien le sucedieron los ya citados Bruno Carranza Ramírez, Cruz Alvarado Velazco, Andrés Sáenz Llorente y Jesús Jiménez Zamora, que se graduaron poco antes de 1850 (Arias, 2002), más Lucas Alvarado Quesada. Un caso muy particular es el de José María Montealegre Fernández, de familia acaudalada y graduado en la muy prestigiosa Universidad de Edimburgo, en Escocia. A él se aludirá después.

\section{Algunos médicos extranjeros}

Ante la escasez de médicos nacionales, su lugar lo desempeñaban varios curanderos. Sin embargo, en distintos momentos y por diversas circunstancias arribaron varios médicos extranjeros, que se afincaron en San José o Puntarenas, el segundo polo comercial del país. Además, otros lo hicieron en las cabeceras de las provincias de Cartago, Alajuela y Heredia, que eran las más pobladas.

Por ejemplo, desde fines de los años de 1830, se instaló en Cartago el inglés Richard Brealey, de quien se dice que era empírico (Arias, 2002). Nació en 1812 en Nottingham, y en Costa Rica se casó con Mary Ann Paynter; murió en 1864 en el país, donde, además de empresario agrícola, fungió como pastor de la iglesia protestante (Murchie, 1981). En 
Revista Herencia, Vol. 34 (2), enero-junio, 2021.

dicha ciudad también residió el estadounidense George Guier Stone, originario de Filadelfia. Él partió hacia Alemania, donde murió soltero, mientras que su hermano Henry, quien era farmacéutico, se casó con Matilde Frexes Sandoval (Murchie, 1981).

En cuanto a Puntarenas, en 1852 arribó ahí el médico colombiano Lucas Angulo Sánchez. Nacido en 1805, proveniente de Los Santos, Panamá -entonces parte de la Gran Colombia-, las circunstancias políticas adversas lo obligaron a autoexiliarse en nuestro país. Llegó con su segunda esposa, Úrsula Rodríguez de Gracia, con quien procreó siete hijos.

Por su parte, en Heredia estaban el guatemalteco Fermín Meza Orellana (Figura 1A), nacido en 1816, así como el colombiano Antonio Pupo Cibiades, quien llegó en 1856 (Arias, 2002). Asimismo, se ignora si en Alajuela ejercía algún extranjero, aunque hay evidencias de que ahí estaba el nacional Sáenz Llorente.
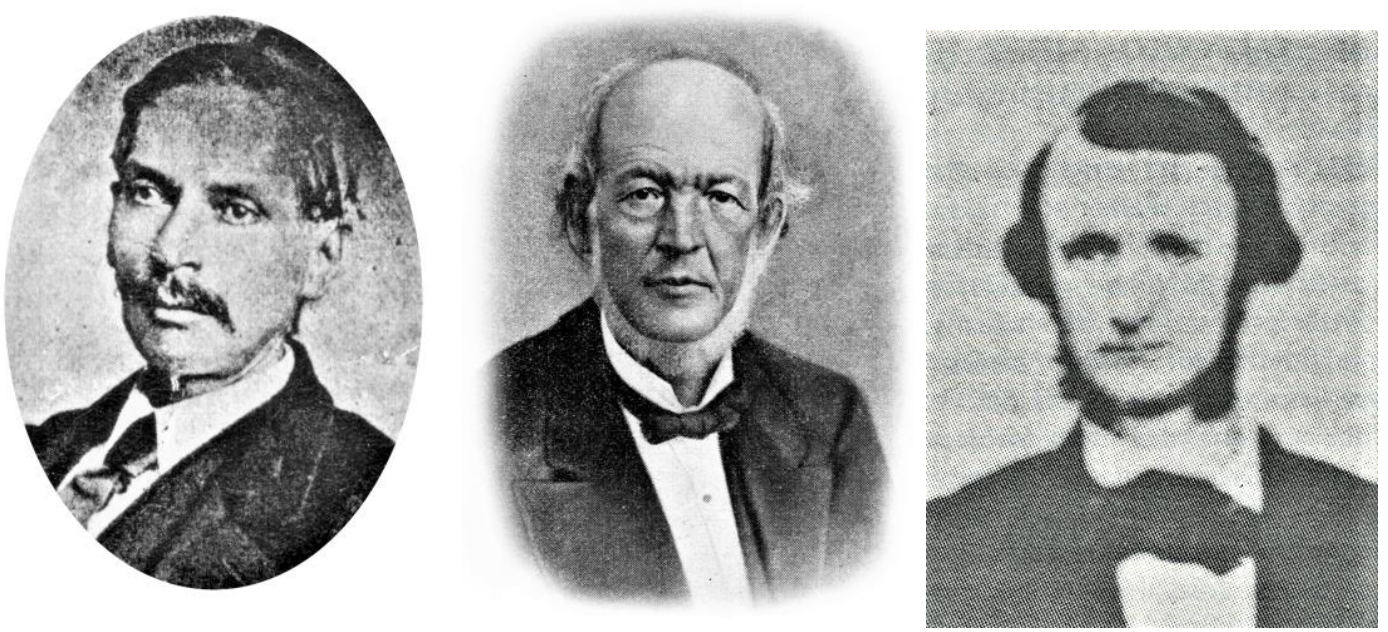

Figura 1. Tres médicos extranjeros: Meza Orellana (A), Toledo Murga (B) y Hogan (C). 
Revista Herencia, Vol. 34 (2), enero-junio, 2021.

En la capital residían varios. Uno fue el guatemalteco Nazario Toledo Murga (Figura 1B), nacido en 1807, quien llegó en 1836 en labores diplomáticas (Arias, 2002). Fue un notable miembro de la Junta de Caridad, que impulsó la creación del Hospital San Juan de Dios, y aconsejó al presidente Juan Rafael (Juanito) Mora Porras para que fundara el Protomedicato de Costa Rica - embrión del Colegio de Médicos y Cirujanos-, para evitar el empirismo. También fue diputado y presidente del Congreso, así como profesor y rector de la Universidad de Santo Tomás. Se casó con Rosa Mattei Goyenaga, con quien procreó dos varones, uno de los cuales fue el también médico Nazario Toledo Mattei.

A él se sumaban dos franceses. Uno era Víctor de Castella Ducoblaud, quien se casó con Josefa Carrillo Morales, sobrina del exgobernante Braulio Carrillo. El otro fue Jean George Alfonso Carit Tlichey, quien llegó al país en 1856, ya casado con la nicaragüense Matilde Eva (Oconitrillo, 1998); su hijo Adolfo también se convertiría en médico, y después donaría el terreno donde se halla ubicado el actual Hospital de la Mujer, conocido antes como Maternidad Carit.

Un caso particular es el del nicaragüense Francisco Bastos, de cuya vida se conoce muy poco.

Finalmente, hubo dos médicos estadounidenses, James (Santiago) Hogan Grey (Figura 1C) y Marquis Lafayette Hine Wickes (Murchie, 1981). Hogan, nacido en Filadelfia, aunque fue atraído hacia California por la "fiebre del oro", después se afincó en Costa Rica; en 1857 se casó con Catalina Guardia Bonilla, con quien tuvo tres hijas. Por su parte Hine, quien nació en Nueva York en 1923, fue el primer cónsul de los EE.UU. en Costa Rica, puesto que ocupó por 20 años; se casó con Mercedes Ramírez Rodríguez, con quien procreó siete hijos. 
Revista Herencia, Vol. 34 (2), enero-junio, 2021.

\section{Los médicos alemanes}

Los médicos alemanes ameritan una sección aparte, por su mejor preparación académica y profesional, así como por su involucramiento directo en los frentes de batalla. Sin embargo, antes es necesario aclarar por qué arribaron a Costa Rica.

En efecto, a mediados del siglo XIX en Europa ocurrían fuertes confrontaciones contra el poder monárquico absoluto, las cuales culminaron en la cruenta Revolución de 1848 . No obstante, al final sus resultados fueron frustrantes para vastos sectores de la población, especialmente en Alemania. A la pobreza generalizada sobrevino una implacable represión policial, por lo que hubo una diáspora hacia América. Fue en ese marco cuando se fundó la Sociedad Berlinesa de Colonización para Centro América, como una especie de válvula de escape para tanta tensión social y política, dado que en dicha región abundaban las tierras para establecer colonias agrícolas (Hilje, 2020).

Uno de los líderes de dicho ente, de capital público-privado, era el ingeniero Alexander von Bülow. Inicialmente establecieron una alianza con una colonia belga que había en Guatemala. Tras fracasar, él emprendió un proyecto de colonización en Bluefields, Nicaragua, que pronto abortó. Fue entonces cuando puso su mirada en Costa Rica, donde se eligió Miravalles, en Guanacaste, para fundar una colonia, iniciada con 37 alemanes, quienes arribaron en junio de 1851; no obstante, tiempo después el proyecto abortó, debido a reclamos de Nicaragua por algunos territorios. 
Revista Herencia, Vol. 34 (2), enero-junio, 2021.

Dada la necesidad de contar con médicos en dicha colonia, es muy posible que así fue como llegó al país Carlos Hartmann. Así se colige de un comentario del viajero y cronista alemán Wilhelm Marr, quien en 1853 acotara que "en Hamburgo fue contratado un médico, el doctor H., y se le proveyó de una farmacia flamante" (Marr, 2002). Se ignora cuál era esa botica, aunque en 1854, junto con su colega Santiago Huzel, Hartmann instaló en Puntarenas la Botica Alemana (Hilje y Torres, 2018).

Es de suponer que también fue así como arribó Franz Ellendorf Bartels, quien parece que era el médico personal del conde Hermann von und zur Lippe (Hilje y Torres, 2018), miembro de la Sociedad Berlinesa, que tuvo casas comerciales en San José y Puntarenas. Aunque no se cuenta con mucha información sobre Ellendorf, sorprende que, a diferencia de la mayoría de sus compatriotas, que fueron víctimas de los lapidaros juicios de Marr, éste lo describiera como "hombre fino y gallardo, había conquistado ya una brillante clientela y sería riquísimo si no tuviese tan buen corazón" (Marr, 2002). Nacido en 1810, a su regreso a Alemania fungiría como cónsul honorario de Costa Rica en Wiedenbrück, su ciudad natal (Hilje y Torres, 2018).

Ahora bien, por fortuna para Costa Rica, a inicios de 1854 arribaron al país, junto con sus esposas, dos médicos graduados en la muy prestigiosa Universidad de Berlín (Hilje, 2013). Uno era Karl Hoffmann Brehmer (Figura 2A), nacido en 1823, en tanto que el otro, Alexander von Frantzius Ritt (Figura 2B), nació en 1821. De convicciones democráticas y republicanas ambos, tuvieron participación activa en las revueltas callejeras asociadas con la Revolución de 1848, como también la tuvo el abogado Fernando Streber, quien en 1852 llegó a Costa Rica como secretario de la Sociedad Berlinesa, ahora interesada en establecer una colonia en Angostura, Turrialba (Hilje, 2020). Y fue justamente Streber quien persuadió a Hoffmann para que se instalara en nuestro país, y éste invitó a su amigo y colega von Frantzius para que lo acompañara. 
Revista Herencia, Vol. 34 (2), enero-junio, 2021.
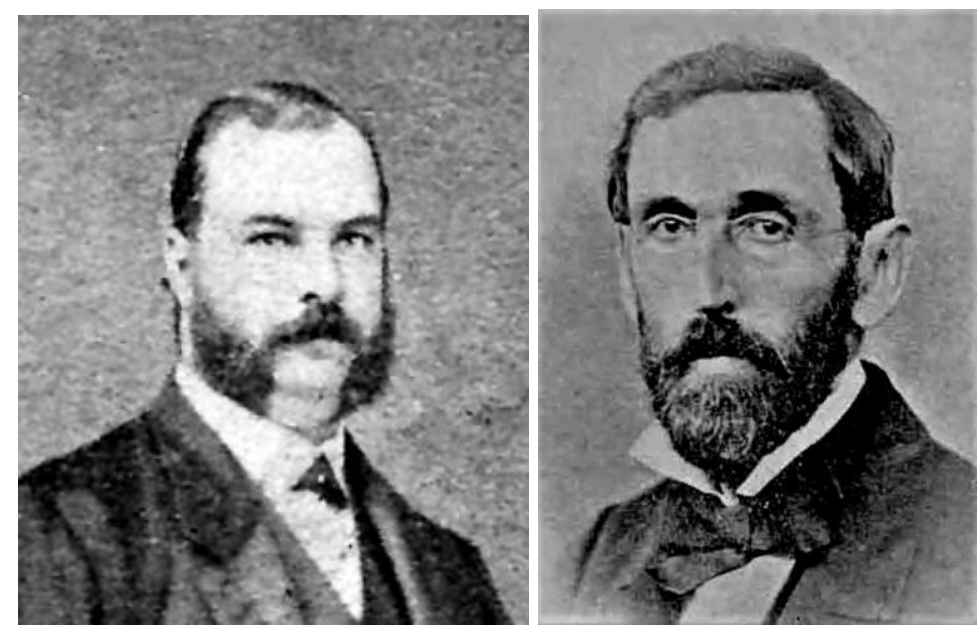

Figura 2. Dos médicos alemanes: Hoffmann (A) y von Frantzius (B).

En realidad, ellos llegaron a nuestro país debido a su interés por explorar nuestra naturaleza, lo que explica que portaran consigo una carta de recomendación del gran naturalista Alexander von Humboldt -que había recorrido gran parte del trópico americano entre 1799 y 1804 -, dirigida al presidente Mora (Hilje, 2013). Sin embargo, puesto que en la Universidad de Santo Tomás no había carreras de medicina o farmacia, no se les pudo contratar como profesores, por lo que debieron dedicarse a ejercer su profesión y en su tiempo libre efectuar sus giras de exploración biológica.

Hoffmann instaló su botica-consultorio frente al costado sur de la Plaza Principal (actual Parque Central). Pronto ganó una gran reputación. En palabras de su colega Toledo, recopiladas por Hilje (2012), "no menos fue estimable el Doctor Hoffmann por sus dotes sociales: amable y sencillo en su trato; tenía por constitución la dulzura tan precisa en el ejercicio de la medicina, como la caridad que engendra un corazón sensible como el suyo. Muy lejos de ser arrebatado por la ávida codicia de los negociantes en medicina, se atrajo desde luego el afecto y todas las consideraciones de los vecinos del país y extranjeros por su generosidad en el ejercicio de su profesión". Con su sólida preparación y su trato, es muy posible que pronto se convirtiera en el médico de cabecera de las familias de alta 
Revista Herencia, Vol. 34 (2), enero-junio, 2021.

posición económica y social.

En el caso de von Frantzius, desde mucho tiempo antes padecía de asma, y percibió que el clima de San José no le sentaría bien, por lo que decidió establecerse en la muy cálida Alajuela. Tuvo la fortuna de que en abril de 1854 el propio don Juanito lo nombró médico de pueblo - una especie de médico comunitario-, cuyo salario era bastante alto, de 100 pesos mensuales (Archivo Nacional- Hacienda- 10183, 28-VII-1856, f. 40), el doble del sueldo de los diputados y jueces. Él adquirió una amplia casa, una cuadra al oeste del actual Parque Central, en la esquina donde hoy está el Almacén Llobet. Sin embargo, a fines de 1857 se mudó a la capital, donde instaló su botica-consultorio.

\section{¡Estalla la guerra!}

Cuando la invasión de Walker era inminente, en la mañana del 10 de marzo de 1856 don Juanito llamó a las armas a la ciudadanía. Ese mismo día recibió una lacónica pero significativa carta de 35 alemanes residentes en San José, ofreciéndose a defender a Costa Rica. Puesto que su caligrafía coincide con la de él, es claro que fue redactada por el ya citado médico Ellendorf, a cuya iniciativa se sumó el farmacéutico Braun, y después sus demás compatriotas (Hilje, 2007; 2013).

Ante la urgente necesidad de contar con un equipo de médicos solventes, era lógico que el jefe de ese equipo fuera Montealegre, quien además estaba casado con Ana María hermana de don Juanito-, pero ni siquiera formó parte de dicho equipo. Aunque podría suponerse que tenía hijos por los cuales velar - se había priorizado como reclutas a los solteros y los casados sin hijos-, tampoco se involucró cuando, dos meses después, la epidemia del cólera morbus asoló las principales ciudades del Valle Central, como se verá 
Revista Herencia, Vol. 34 (2), enero-junio, 2021.

después.

Esta actitud podría explicarse porque, en realidad, no era médico, sino apenas cirujano, algo así como un técnico en medicina, según lo ha demostrado Arias (2002). Esto lo hubiera puesto en serias dificultades ante la enorme tarea sanitaria provocada por la epidemia, por lo que prefirió mantenerse al margen. La otra hipótesis es que, al igual que el resto de su familia y otros miembros de la oligarquía cafetalera, se oponía a enfrentarse a Walker (Arias, 2002). Además, cuando en 1859 ese grupo derrocó a don Juanito, eligió a Montealegre - por entonces viudo-como presidente. Aún más, el 30 de setiembre de 1860 don Juanito fue sentenciado por un Consejo de Guerra, en Puntarenas, el cual tenía autorización del gobierno para hacerlo; consumada su muerte por fusilamiento, al día siguiente un Consejo de Gobierno ampliado, presidido por Montealegre, no solo refrendó ese acto, sino que también acordó fusilar al general José María Cañas Escamilla (Fernández Guardia, 1980), concuño suyo.

Llama la atención que don Juanito nombrara al Dr. Hoffmann como Cirujano Mayor del Ejército Expedicionario, lo cual hizo la víspera de convocar al pueblo a las armas, según consta en la Orden General Constitutiva del Estado Mayor. Nótese que esto ocurrió antes de que los alemanes le enviaran su carta de apoyo, lo cual denota cuánta confianza le tenía don Juanito y cuán acertado era el juicio de Rohrmoser (Hilje 2010), al calificarlo como el mejor entre los mejores. Solo con credenciales como estas - de elevada calidad profesional y de plena integridad como ser humano-, un presidente podría poner en manos de un extranjero la seguridad sanitaria de su ejército.

Como médicos de su equipo, en ese mismo documento se consigna a Cruz Alvarado Velazco (Figura 3A), Fermín Meza Orellana y Manuel María Esquivel - no Chepe-, así como al ayudante Carlos F. Moya y a los "enfermeros asistentes" Joaquín Lara, Carlos Vásquez y Mercedes Azofeifa, todos varones. En realidad, Esquivel se mantuvo en la 
Revista Herencia, Vol. 34 (2), enero-junio, 2021.

capital, mientras que en días posteriores, al equipo se sumarían en Rivas los doctores Andrés Sáenz Llorente (Figura 3B) y Francisco Bastos -que, al parecer, estaban en Liberia-, al igual que Meza Orellana, quien gozaba de una licencia temporal. Asimismo, al parecer, la viandera Francisca (Pancha) Carrasco Jiménez, símbolo femenino de nuestra gesta, también realizó labores de enfermería.
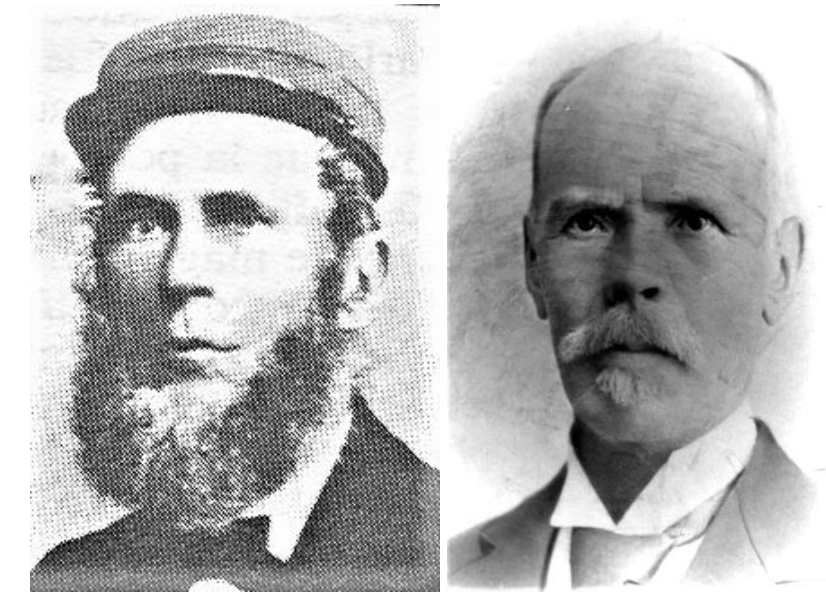

Figura 3. Dos médicos costarricenses: Alvarado Velazco (A) y Sáenz Llorente (B).

Es oportuna una digresión, aquí, para referirse a los miembros del equipo médico. El guatemalteco Meza Orellana era siete años mayor que Hoffmann - con 33 años de edad entonces-, en tanto que Alvarado Velazco y Sáenz Llorente eran tres años menores que él. En cuanto a sus esposas, el primero se había casado en 1842 con María Engracia Noguera Mena, mientras que los otros dos, solteros entonces, lo harían años después con la nicaragüense Manuela Carrillo Morales y con Mercedes Sandoval Pérez, respectivamente. De Esquivel, Moya, Bastos y los enfermeros no nos fue posible recabar mayor información.

La primera batalla contra los invasores ocurrió el 20 de marzo de 1856 en la hacienda ganadera Santa Rosa, en Guanacaste (Obregón, 1991). Fue ganada en apenas 14 minutos, con un saldo de 20 muertos y 31 heridos, quienes fueron auxiliados por Alvarado Velazco, 
Revista Herencia, Vol. 34 (2), enero-junio, 2021.

quien era el médico de la tropa enviada a dicha hacienda, encabezada por el general José Joaquín Mora. En Liberia, donde acampaba el ejército, poco después de enterarse de la fulminante victoria, en una carta remitida a su hermano, don Juanito expresaba: "Deseando que se les dé la más cumplida asistencia a los oficiales y soldados heridos, mando a Ud. al Dr. Hoffmann con el practicante Moya y los utensilios que necesita el Dr. Alvarado" (Boletín Oficial de Costa Rica. Alcance. No. 179, 25-III-1856, p. 390).

Hoffmann y Moya pronto se dirigieron a Santa Rosa para atender a los heridos, a la vez que ordenaron trasladarlos hasta Liberia, para poder cuidarlos mejor. De hecho, Alvarado Velazco permaneció ahí atendiéndolos, mientras el ejército avanzaba hacia Nicaragua, para enfrentarse a los filibusteros. La atención fue tan esmerada -él estuvo ahí por varias semanas, al punto de que no pudo viajar a Nicaragua-, que de los 31 heridos apenas murió uno, debido al tétano, lo que hace suponer que fue la dificultad para desinfectar el equipo de cirugía lo que provocó este deceso, ante la falta de higiene propia del improvisado "hospital de sangre".

Ya en territorio nicaragüense, el 7 de abril se envió un batallón de 300 hombres al estratégico puerto lacustre de La Virgen (Obregón, 1991). Al llegar al lugar, una columna fue recibida con fuego desde las instalaciones de la Compañía Accesoria del Tránsito, que operaba los vapores en el río San Juan y el lago de Nicaragua. En nuestras filas hubo apenas un herido, el sargento Félix Jiménez, quien recibió dos balazos en el hueso de una pierna. Trasladado adonde acampaba el ejército, Hoffmann decidió amputarle la pierna, pues era diestro en hacerlo, a juzgar por el siguiente juicio de Toledo (Hilje, 2012): "Habiendo hecho un estudio especial de la terapéutica externa, se distinguió siempre por su tino práctico en la pronta y fácil ejecución de las operaciones de cirugía". No obstante, durante el traslado Jiménez perdió mucha sangre, por lo que murió poco después de operado. 
Revista Herencia, Vol. 34 (2), enero-junio, 2021.

El día 8 de abril nuestro ejército arribó a la ciudad de Rivas, de lo cual Walker se enteró poco después. Conocedor de las posiciones de los nuestros, concibió un plan para atacar por sorpresa muy temprano el 11 de abril y así tomar el cuartel general y capturar a todo el Estado Mayor -incluyendo a don Juanito, Hoffmann y otros alemanes-, y así vencer con rapidez. Eso sí, aunque su ardid no pudo concretarse, dicha batalla tuvo un alto precio en vidas, dolor y sufrimiento. Los acontecimientos de ese día aparecen prolijamente detallados por Obregón (1991).

Concentrados los fuegos en la plaza ubicada frente a la iglesia de la ciudad, así como en unas pocas cuadras aledañas, por todas partes llovían las balas, mientras que en las estrechas callejuelas se topaban los contrincantes de un bando y otro en combates cuerpo a cuerpo, recurriendo a sables, puñales y bayonetas. En alusión a esas primeras horas de confrontación, el doctor Sáenz Llorente evocaría que "el fuego era terrible, las balas entraban por muchas partes y tuve que hacer la primera cura a los heridos echado de barriga para que no me matasen. Estuve después en otras casas de la misma manzana, en las cuales había también numerosos heridos" (Sáenz, 1940).

En efecto, durante la mañana los heridos fueron atendidos en los solares de algunas casas cercanas, pero "en la tarde nos trasladamos a un edificio que llamaban la casa de [José María] Maliaño, donde se improvisó un hospital" (Sáenz, 1940); dicha edificación aún existe (Figura 4). Y, a pesar de su tamaño y de las inadecuadas condiciones de higiene, debió albergar nada menos que a 271 heridos, cuyos nombres consignó Hoffmann en una lista fechada el 15 de abril. En ella consta, para cada paciente, su grado militar, su localidad de residencia, el lugar de la herida y la magnitud de ésta (leve, semi-grave, grave, muy grave y gravísima). A ellos se sumaban unos 30 con heridas leves, quienes permanecían en casas particulares o en las casas-cuarteles desde las cuales combatieron. 


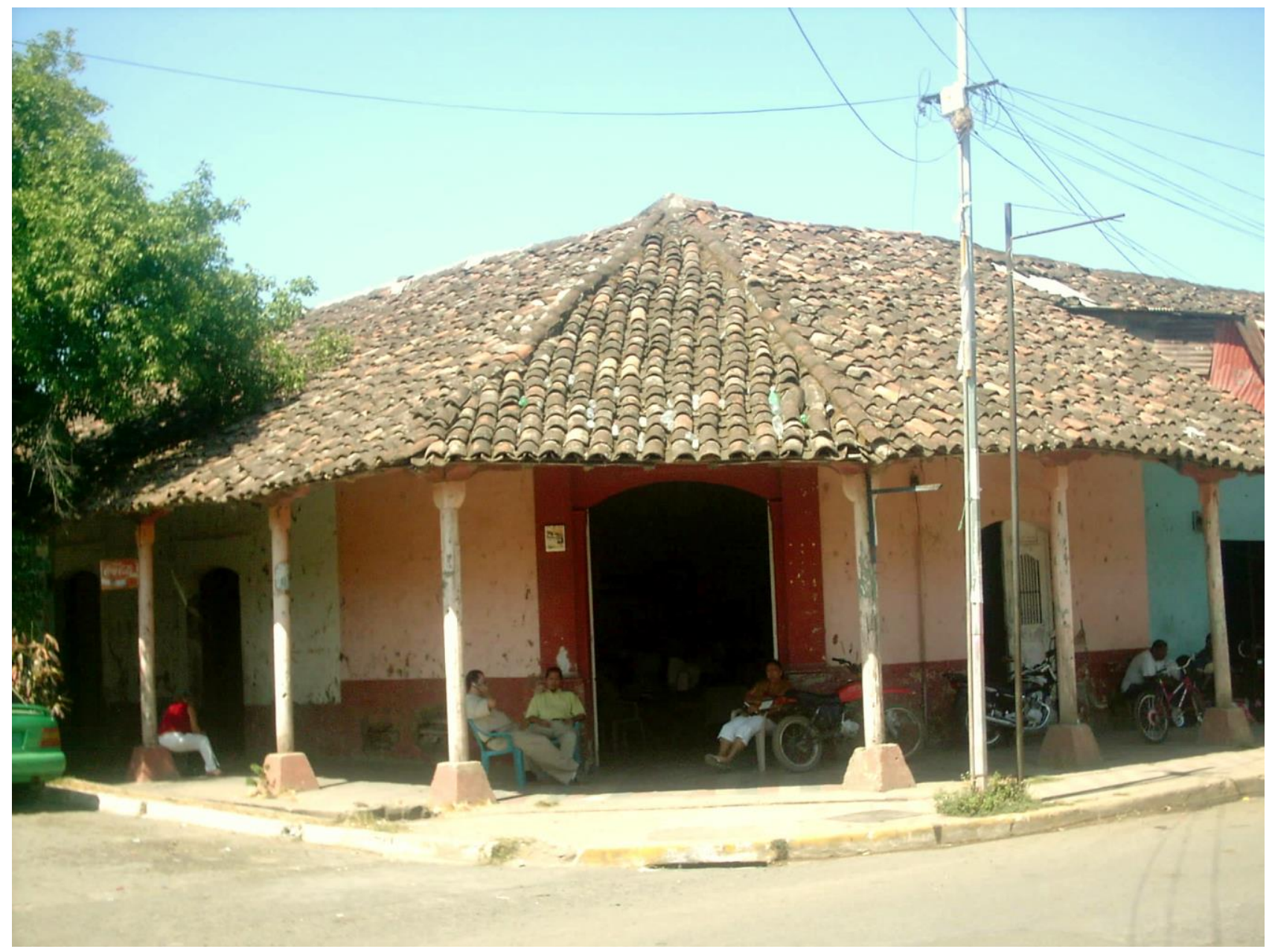

Figura 4. Casa donde estuvo el hospital de campaña, en la actualidad. Cortesía: Raúl Arias.

Aunque, tras unas diez horas de combate se logró la victoria y Walker escaparía en la madrugada del día siguiente, el saldo fue realmente pavoroso. Según cálculos de Sáenz Llorente, en nuestras filas "hubo trescientos heridos o más y muy cerca de quinientos muertos". Aunque estas cifras han sido aceptadas como correctas, en años recientes Arias (2007) aclaró que en realidad hubo 231 heridos y 140 fallecidos, mientras que entre los filibusteros hubo 236 muertos y un número no determinado de heridos; la discrepancia con los 271 heridos consignados por Hoffmann se debe a que algunos murieron después, debido a las heridas o al cólera, por lo que Arias los contabilizó como muertos. 
Revista Herencia, Vol. 34 (2), enero-junio, 2021.

Como testigo de excepción de las aterradoras escenas presenciadas en la casa de Maliaño, Sáenz Llorente relataría que "si un hospital de guerra es siempre una cosa terrible, en aquella época, en que aún no se conocían entre nosotros los anestésicos, era un espectáculo del que no se puede tener idea cabal sin haberlo visto. iCuánta miseria y cuánto sufrimiento!". De hecho, para el día 15 habían fallecido cinco combatientes, mientras que muchos requirieron intervenciones quirúrgicas para extraer las balas, así como para limpiar y suturar heridas profundas.

Pero también hubo que realizar amputaciones de piernas, brazos o dedos a siete combatientes, mientras estaban despiertos, para lo cual se recurría a embriagar al paciente para relajarlo y así atenuar el dolor. Según algunos médicos consultados, estas amputaciones podían efectuarse en menos de media hora, sobre todo si consistían en cortes en las articulaciones del hombro, el codo o la rodilla. De ser necesario cortar huesos, se hacía con navajas o sierras, tras lo cual se vertía aceite hirviendo, para cauterizar las venas y capilares y evitar hemorragias.

Como testimonio de la denodada labor de Hoffmann, en un parte militar del general francés Pedro Barillier, expresaba: " $¥ Y$ cuánto celo y acierto en los inteligentes cuidados prodigados a nuestros numerosos heridos por el señor Cirujano en Jefe Carlos Hoffmann!" (Boletín Oficial de Costa Rica, No. 188, 30-IV-1856, p. 423-424). Obviamente, no se trataba solo de éste, sino de todo el equipo de médicos y enfermeros, que realmente se tornó insuficiente para atender a tanto herido; además, ante tanta demanda, las medicinas empezaron a agotarse.

Por lo anterior, hubo que hacer gestiones para adquirir tres cajas de medicinas en San José, cuya compra se efectuó el 29 de abril. Con esta remesa deberían arribar como refuerzos von Frantzius y Carranza Ramírez. Aunque varios autores han dicho que ambos llegaron a Rivas con los medicamentos, esto no ocurrió así (Hilje, 2013). Al parecer, 
Revista Herencia, Vol. 34 (2), enero-junio, 2021.

posteriormente se les dio la orden de permanecer en Puntarenas, donde se había instalado un hospital de campaña para recibir a combatientes que desde San Juan del Sur eran repatriados por barco (Figura 5), debido a la aparición del cólera morbus en Rivas; los encargados de tan delicada labor fueron el general José María Cañas y Hoffmann (Boletín Oficial de Costa Rica, No. 189, 3-V-1856, p. 428). Dicho hospital estuvo a cargo del Dr. Hine - a pesar de ser el cónsul de EE.UU. en Costa Rica- y después de Hogan. Fue esta misma situación la que obligó a establecer un hospital de campaña en Liberia, para los enfermos que venían por tierra. Estuvo bajo la tutela de Hine. Al parecer, ahí lo secundó el colombiano Angulo Sánchez.

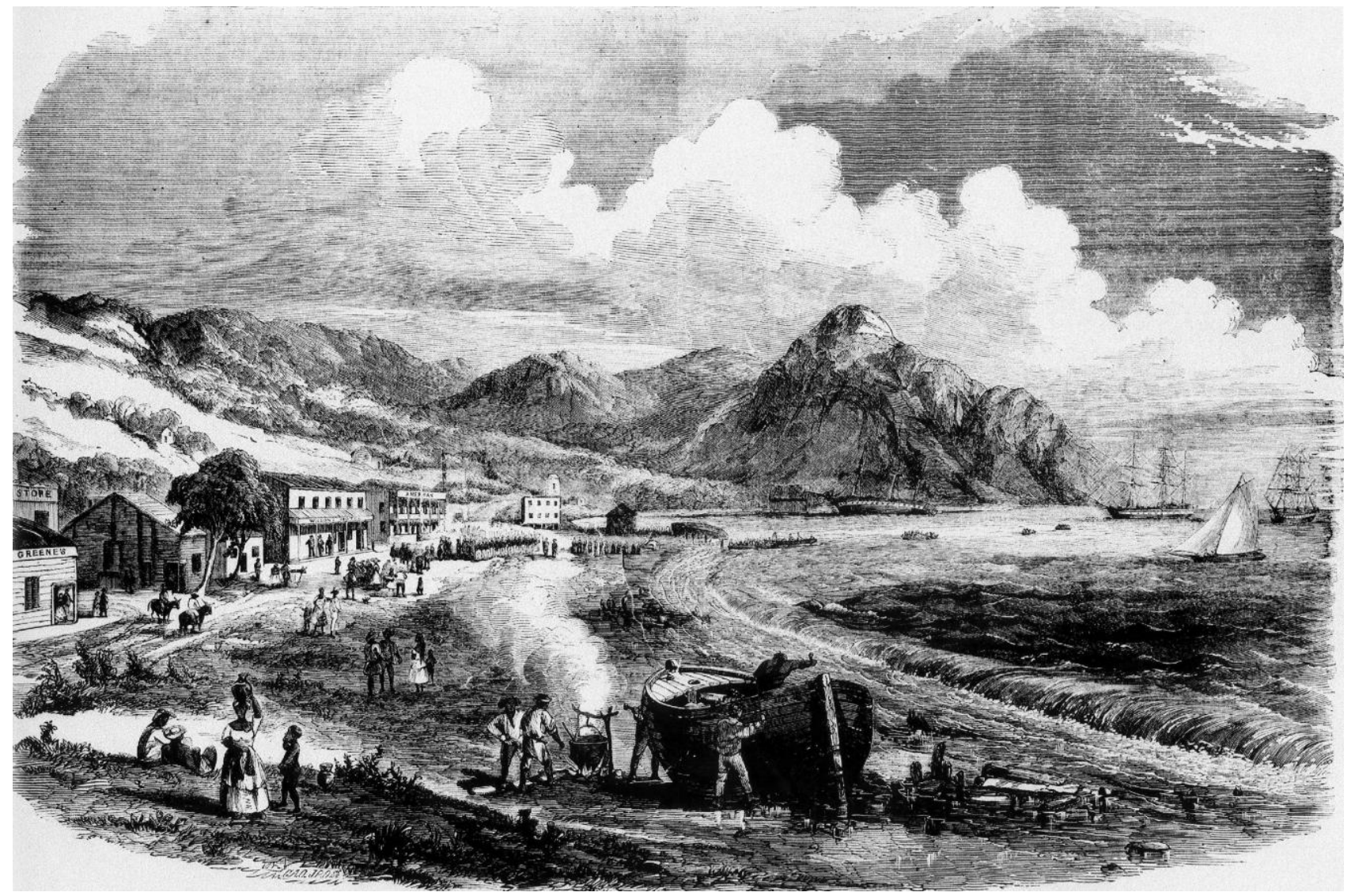

Figura 5. Repatriación de combatientes enfermos, en San Juan del Sur.

Fuente: Frank Leslie's Illustrated Newspaper. 
Revista Herencia, Vol. 34 (2), enero-junio, 2021.

Para concluir esta sección, es oportuno mencionar que el médico Manuel María Esquivel -que había permanecido en la capital- viajó como médico de un batallón de 500 refuerzos que salió el 21 de marzo, rumbo a Nicaragua, al mando del teniente coronel Florentino Zeledón. No obstante, se estacionaron en Puntarenas hasta abril, pero después se dirigieron a Liberia, para apoyar a Hine. Mientras laboraba ahí, en cierto momento debió viajar al puerto de El Coco, para atender a los enfermos transportados en el barco Telemby, que debían ser remitidos a Liberia.

\section{Frente a la epidemia del cólera}

Si la atención sanitaria de los heridos en Rivas - razón por la cual don Juanito rehusó perseguir a Walker hasta su cuartel en Granada- era de por sí complicada, lo verdaderamente catastrófico estaba por venir. En efecto, el 20 de abril se manifestó el primer caso de cólera morbus, y poco a poco el mal empezó a extenderse entre nuestras tropas.

Para Hoffmann, los síntomas observados no le eran desconocidos pues, según Toledo (Hilje, 2012), antes de graduarse hizo un internado y sobresalió "como el asistente más capaz y humano en uno de los hospitales de colerientos". Es posible que fuera en 1849 en el hospital La Charité, perteneciente a la Universidad de Berlín, durante la segunda pandemia mundial. Por cierto, para esa época von Frantzius debió realizar autopsias de muertos por el cólera en el hospital de Breslau (Hilje, 2013). 
Revista Herencia, Vol. 34 (2), enero-junio, 2021.

En palabras del propio Hoffmann, en los afectados inicialmente se percibía "debilidad general, depresión de alma, mal gusto y dolores del estómago, evacuaciones, un sudor profuso y helado". Estas copiosas evacuaciones eran ralas, parecidas al "agua de arroz", e igualmente los enfermos sufrían vómitos, lo que provocaba deshidratación y una intensa sed, aunque no había fiebre; por el contrario, la piel se tornaba gélida. A estos indicios se sumaban la postración y la ansiedad, calambres, hundimiento de los ojos, boca entreabierta, fosas nasales muy dilatadas y manos muy arrugadas. La muerte podía ocurrir en menos de 12 horas, por la incesante pérdida de agua, con la consecuente merma de electrolitos o sales minerales, que determinan la transmisión de los impulsos nerviosos y participan en otras importantes funciones fisiológicas (Mata, 1992).

Nadie habría imaginado entonces que, en realidad, el agente causal del cólera era una bacteria (Vibrio cholerae). Por entonces, este y otros males eran imputados a miasmas supuestos vapores emitidos por aguas y materias putrefactas-, así como también al riguroso efecto de climas muy cálidos. De hecho, la denominación de este mal como cólera morbus proviene de los términos chole (= bilis) y morbus (enfermedad), dado que se suponía que dichos factores provocan la irritación del hígado, lo que origina una excesiva secreción de bilis. Habría que esperar 30 años para que, en 1884, el médico alemán Robert Koch determinara el origen bacteriano de la enfermedad.

Alarmado por tan imprevista situación, don Juanito consultó con los médicos y su Estado Mayor. Al parecer, hubo consenso en que la afección se debía al muy cálido clima de Rivas. Y fue así como el 25 de abril convocó a las tropas en la plaza principal de la localidad, para dar la orden de regresar a Costa Rica, al señalar que "no hay deshonor en cejar ante la influencia de un clima insalubre". En su mente quizás estaba la ilusión de que, con el retorno al país, nadie más se enfermaría y los afectados poco a poco se recuperarían. 
Revista Herencia, Vol. 34 (2), enero-junio, 2021.

En realidad, según Mata (1992), el contagio ocurrió sobre todo por el consumo de agua captada de los pozos que había en los solares de las casas en Rivas. Además, ni allá ni en Costa Rica había letrinas, por lo que la gente defecaba a campo abierto y, si bien se estaba en la estación seca, las lluvias de abril, aunque esporádicas, podrían haber favorecido la contaminación de las fuentes de agua. Asimismo, no existía la costumbre de lavarse las manos, y los combatientes permanecían hacinados en unas pocas casas.

Sin embargo, al ordenar el retorno de las tropas (Figura 6), se incurrió en un grave error de carácter epidemiológico, pues más bien se favoreció la diseminación del bacilo. Durante la travesía, el contagio y las muertes siguieron aumentando, al punto de que las tropas regresaron a Liberia muy diezmadas. Y, ya en sus hogares, el bacilo se propagó con suma rapidez, pues no había alcantarillado y las aguas de uso doméstico corrían por acequias expuestas. En pocas semanas el embate del bacilo fue tal, que cada día morían unas 111 personas en promedio, hasta matar cerca del $10 \%$ de la población del país, que por entonces era de unas 100.000 personas (Arias, 2002). 


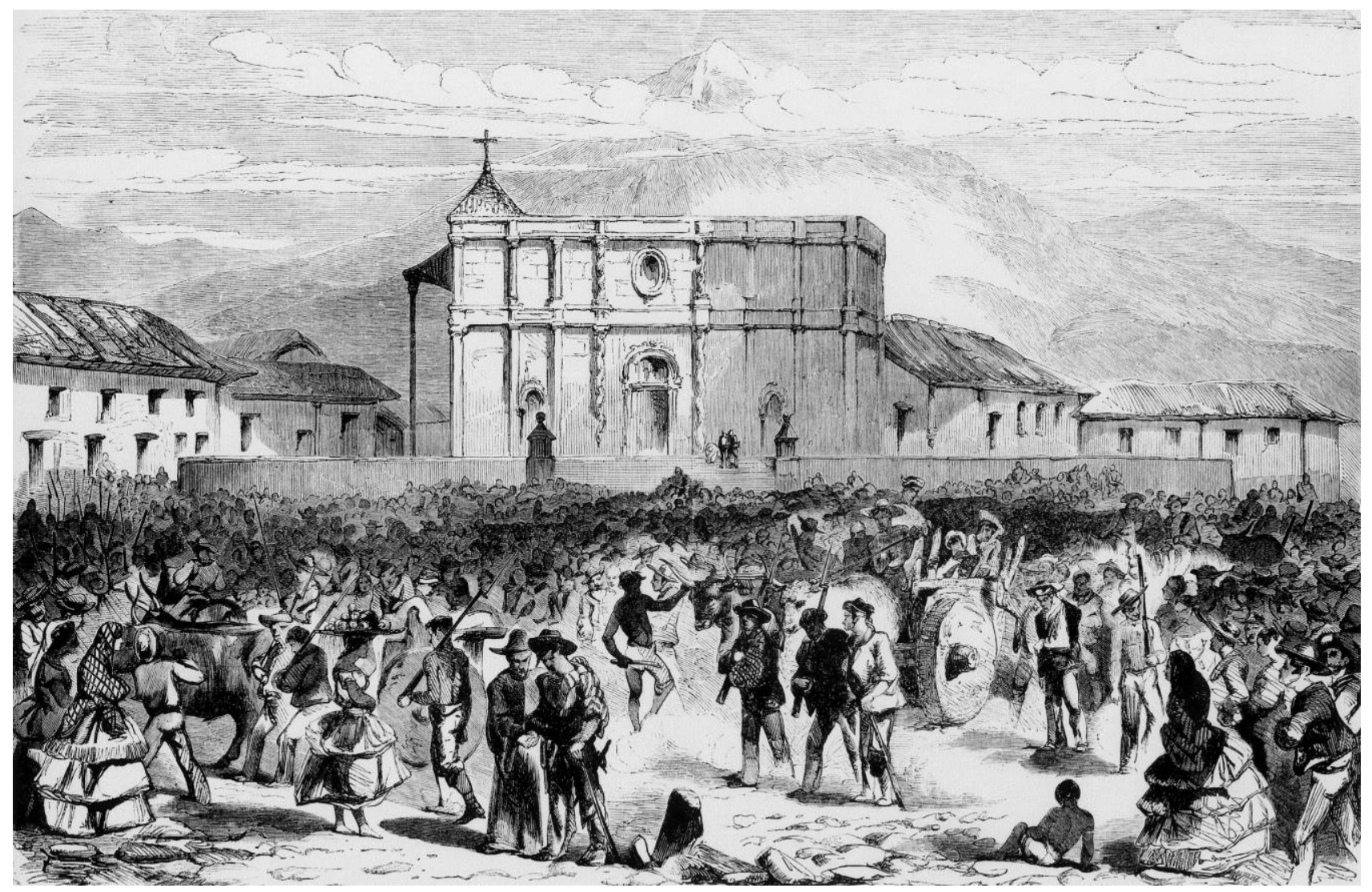

Figura 6. Recibimiento de las tropas en la Plaza Principal.

Fuente: Frank Leslie's Illustrated Newspaper.

Ante la imposibilidad de abatir el mal, el gobierno recurrió incluso a curanderos, mientras que en la capital nombró como médicos de pueblo a Hogan y su compatriota William Irvine, quien había llegado al país a fines de marzo (Hilje, 2013). En Heredia se hizo lo propio con Antonio Pupo, y también se le pagaron algunos honorarios a Richard Brealey. Asimismo, es de destacar que a otros médicos se les compraron medicinas, como sucedió con Carranza Ramírez, Meza Orellana, Alvarado Velazco y Montealegre Fernández, el gran ausente de la Campaña Nacional. 
Revista Herencia, Vol. 34 (2), enero-junio, 2021.

Sin embargo, en esos días de debacle, cuando imperaban el dolor y la desesperanza, emergió la carismática figura de Hoffmann. En un comunicado del 12 de mayo, anunciaba que el Hospital San Juan de Dios -obra de su compatriota Franz Kurtze, y aún sin concluir - , estaba preparado para atender a los combatientes heridos o enfermos. Dicho aviso apareció en la prensa dos días después (Boletín Oficial de Costa Rica, 14-V-1856, No. 192, p. 439 y 440), junto con un extenso texto intitulado Advertencia sobre el cólera, en el cual daba consejos de carácter preventivo (evitar frutas y bebidas fermentadas, consumir reconstituyentes y mantener una actitud anímica positiva) como curativo (un medicamento consistente en gotas amargas vertidas en coñac o vino fino, que él denominó medicina anti-colérica, mixtura tónica o esencia tónica) para enfrentar la enfermedad.

Es posible que, para ganar tiempo, el primer comunicado circulara primero como un bando que se adhería a las paredes, pues antes de que apareciera en la prensa, ya había surtido efecto. Así se capta del comentario "siguen llegando y recibiendo los cuidados del Sr. Dr. Hoffmann, que los atiende con un esmero y cariño de padre" (Boletín Oficial de Costa Rica, 14-V-1856, No. 192, p. 441), en clara alusión a que Hoffmann especificaba que las víctimas podían ser auxiliadas en sus propias casas, con la condición de que, una vez recuperadas, acudieran a su casa para darles seguimiento.

Es oportuno citar que en octubre, cuando la epidemia del cólera había cesado, en el Periódico Alemán de Costa Rica (Costa Rica Deutsche Zeitung), fundado por Hoffmann, Streber y Kurtze, él consignó lo siguiente: “Después de que a mediados de julio de este año había desaparecido el cólera como epidemia, tanto en la capital como en provincias, hasta fines de agosto se presentaron todavía casos aislados". En efecto, Mata (1992) sostiene que esto ocurrió debido a la combinación de dos factores: a) murieron los individuos susceptibles a la enfermedad, lo que redujo mucho el inóculo o fuente de ésta, y b) posiblemente hubo un muy alto porcentaje de personas infectadas (quizás el $75 \%$ de la población), algunas de los cuales se curaron, pero en muchos la afección fue leve o 
Revista Herencia, Vol. 34 (2), enero-junio, 2021.

moderada y lograron quedar inmunizados.

Sin embargo, no debe descartarse el efecto positivo de varias medidas impuestas por el gobierno (cierre de iglesias y ventas públicas masivas, prohibición de aglomeraciones de gente, velas y funerales, etc.) en el cese de la epidemia, así como del medicamento desarrollado por Hoffmann.

Cabe destacar que el hecho de que la calificara como tónico, revela que Hoffmann pretendía favorecer la digestión, para reducir la excesiva secreción biliar asociada con el cólera. No obstante, el licor fino - al igual que las sustancias ácidas - destruye al bacilo casi al instante (Mata, 1992), por lo que, sin proponérselo, Hoffmann estaba recomendando matar al bacilo. Eso sí, esto funciona únicamente de manera preventiva, antes de que la bacteria alcance el intestino y colonice la mucosa del duodeno, que es donde se multiplica en forma masiva y libera una toxina que es la causante del cólera, y que no es afectada por el alcohol ni por los ácidos (Mata, 1992).

Aunque no es posible determinar cuánto contribuyó este medicamento en enfrentar la epidemia, Hilje (2013) analiza varias evidencias que sugieren que sí ayudó. Por ejemplo, como a diario morían tantas personas, se suprimieron los funerales y sus cadáveres eran recogidos en sus casas, apilados en carretas y transportados hacia los cementerios, donde se les lanzaba en fosas comunes. Es de suponer que, debido a las profusas diarreas, en los cadáveres permanecían residuos de materias fecales, lo que exponía a los recolectores y los sepultureros al bacilo, pues tenían que manipularlos. El hecho de que, por disposición del gobierno, a estos personajes se les diera coñac mientras realizaban sus ingratas labores, muy posiblemente los libraba del contagio. 


\section{En las batallas fluviales}

El río San Juan representó el eje estratégico-militar de toda la Campaña Nacional, pues por él transitaban desde San Juan del Norte (Greytown) hasta el puerto lacustre de La Virgen los vapores en los que Walker trasegaba soldados, armas y víveres desde EE.UU., de manera continua. Además, el ejército filibustero contaba con destacamentos en tres sitios clave a lo largo del río: La Trinidad, el Castillo Viejo y el fuerte de San Carlos.

En la primera etapa de la Campaña, el grueso del ejército se dirigió a Guanacaste, por lo que las ciudades del Valle Central quedaban desprotegidas. Por tanto, para evitar una incursión filibustera por el río San Juan y su afluente, el Sarapiquí, don Juanito dispuso enviar un batallón, conformado por sendos destacamentos que había en Muelle y Cariblanco (Hilje, 2013) y 50 alajuelenses, encabezados por el general Florentino Alfaro Zamora. El médico era el cartaginés Lucas Alvarado, nacido en 1819 y casado con Micaela Echandi Bonilla.

Temprano el 10 de abril, la tropa fue atacada por unos 100 filibusteros en el estero del río Sardinal - tributario del Sarapiquí-, con un saldo de un muerto, dos desaparecidos y ocho heridos en nuestras filas, entre ellos el general Alfaro, quien recibió un balazo en la parte superior de su brazo derecho. La gravedad de la herida justificó que el médico recomendara su amputación. Enterado de esto José María Alfaro — hermano de la víctima y exjefe de Estado-, buscó a von Frantzius en Alajuela y le solicitó que lo acompañara hasta Sarapiquí. Al llegar allá, al herido ya lo traían hacia Alajuela y, al topárselo en La Virgen, con gran pericia von Frantzius le pudo salvar el brazo. 
Revista Herencia, Vol. 34 (2), enero-junio, 2021.

Además, como consecuencia de lo ocurrido en Sardinal, Manuel José Carazo Bonilla, ministro de Guerra, ordenó que "establezca en esa ciudad un hospital de sangre, en donde deben ser curados, al cuidado del Dr. Frantzius, a expensas del gobierno y con el mayor esmero, los heridos que vengan de Sarapiqui'". Por fortuna, esa vez no hubo más combates en las cercanías del río San Juan.

Ahora bien, una vez superada la epidemia, tuvo lugar la segunda etapa de la Campaña, pues Walker se había fortalecido, al punto de haberse convertido en presidente de Nicaragua. Para entonces, la salud de Hoffmann se había deteriorado seriamente, por lo que no pudo sumarse a las tropas. Al respecto, varias evidencias sugieren que el estrés severo y crónico derivado de tantas adversidades sanitarias afectó de manera irreversible su salud, lo que posiblemente impidió que fuera nombrado director del Hospital San Juan de Dios y su lugar fuera ocupado por Hogan. Peor aún, tuvo que dejar de ejercer su profesión, por lo que en 1858 el gobierno le asignó una pensión vitalicia, que pudo disfrutar por apenas unos meses, pues falleció el 11 de mayo de 1859, con apenas 35 años de edad. Para entonces el gobierno aún le adeudaba parte de los 2709 pesos -en una época en que un ministro devengaba 1920 pesos al año-, por múltiples gastos en los que incurrió durante la guerra, y que no dudó en pagar de su propio bolsillo.

Para retornar a los acontecimientos bélicos, al reanudarse la Campaña Nacional, quizás temiendo lo peor, por la inevitabilidad de reingresar a territorios donde cundían los miasmas, a Hogan le correspondió preparar las medicinas para el ejército, y fue así como, en un documento intitulado Lista de remedios (con un baúl) para Campaña, Estado Mayor, él especificó las que eran pertinentes y detalló el contenido de cada gaveta de dicho baúl. Como era de esperar, no podía faltar la mixtura tónica de Hoffmann (Archivo Nacional- Guerra- 4694, 6-XII-1856), lo cual sugiere fuertemente lo eficaz que era para prevenir la afección por el cólera. 
Revista Herencia, Vol. 34 (2), enero-junio, 2021.

En esta segunda etapa de la Campaña Nacional, entre noviembre y diciembre de 1856 nuestras tropas marcharon hacia los frentes de batalla, que ahora eran dos (Obregón, 1991).

Un batallón, liderado por el general Cañas salió hacia Liberia y Nicaragua, con el auxilio de Bernabé Bermúdez y el alemán Ellendorf, quien había permanecido como médico "de reserva" en la capital durante la primera etapa de la Campaña.

Por su parte, el batallón enviado al río San Juan se subdividió en dos, los cuales partieron de la capital en diferentes fechas. El de vanguardia se dirigió a Muelle, en San Carlos, para navegar por el río San Juan y atacar el bastión filibustero de La Trinidad. Su médico era Bastos, auxiliado por Moya. Sin embargo, pareciera que Bastos no era muy competente, por lo que tuvo conflictos continuos con su jefe, el mayor Máximo Blanco Rodríguez, quien en una ocasión incluso ordenó darle 50 palos o golpes si no curaba a los enfermos, pero después fue perdonado. En cuanto al batallón de retaguardia, encabezado por el general José Joaquín Mora, siguió la misma ruta, y tenía como médico a Alvarado Velazco. Cuando llegaron al San Juan, ya el primer batallón había infligido importantes derrotas a los filibusteros.

Días después, tomado el fuerte de San Carlos, ubicado a la entrada del lago de Nicaragua, Alvarado Velazco instaló un hospital de campaña para dar servicios a todos quienes participaban en las batallas fluviales. Asimismo, en cierto momento a Ellendorf le solicitaron desplazarse hacia la isla de Ometepe, en el lago, donde se había instalado otro hospital. En sus memorias, el capitán Faustino Montes de Oca narra que mientras estaba anclado un barco frente a esa isla, Ellendorf fue llamado de urgencia a socorrer a su capitán, afectado por el cólera, y lo libró del peligro en menos de 24 horas, pero no indica cómo lo hizo (Obregón, 2007). 
Revista Herencia, Vol. 34 (2), enero-junio, 2021.

En realidad, los enfrentamientos ocurridos en el río San Juan en las primeras semanas fueron de tal sagacidad por parte del mayor Blanco, que fue posible incautar todas las naves filibusteras y los tres sitios clave sin derramar una gota de sangre, lo cual facilitó las labores sanitarias a los médicos y enfermeros.

No obstante, después sobrevendrían problemas serios, debido al feroz contrataque filibustero en La Trinidad, el Castillo Viejo, el fuerte de San Carlos y Ometepe, a lo cual se sumaron los combates en tierra firme, es decir, en San Jorge y la segunda batalla de Rivas. Según Arias (2002), en ellas murieron 191 combatientes y hubo 10 heridos. Llama la atención que en los documentos históricos casi no hay menciones sobre el cólera durante la segunda etapa de la Campaña.

\section{Comentarios finales}

La inevitable Campaña Nacional de 1856-1857, que atentó contra el pujante desarrollo económico y social que Costa Rica atestiguaba hasta entonces, significó también un desgarre en términos sociales y humanos, debido a las víctimas - directas o indirectasde los fusiles, los sables, las bayonetas y la epidemia del cólera. Sin embargo, la catástrofe pudo haber sido aún más grave, si no se hubiera contado con los aportes de varios médicos extranjeros que, junto con los nacionales y sus ayudantes, supieron enfrentar tan seria crisis sanitaria. Asimismo, su labor se extendió hacia los combatientes de otros países hermanos, pues para la segunda etapa de la Campaña Nacional se había forjado una alianza de nuestras tropas con las de los demás países centroamericanos, lo cual hizo posible la capitulación de Walker, el 1o de mayo de 1857 en Rivas. 
Revista Herencia, Vol. 34 (2), enero-junio, 2021.

Por eso este año, al conmemorarse el bicentenario de la independencia de los países centroamericanos, por justicia histórica es necesario evocar las oportunas y abnegadas acciones de todos ellos, de modo que este artículo sirva para tributarles un homenaje, y a la vez contribuya a inmortalizar su memoria.

\section{Agradecimientos}

Dedico este artículo a la memoria de don Arturo Robles Arias ( $\left.{ }^{\dagger}\right)$, destacado médico y descendiente de Carlos von Bülow, sobrino del ingeniero y estratega militar alemán Alexander von Bülow, muerto cuando regresaba de Rivas, tras defender con gallardía nuestra patria. Agradezco a Diego Ruiz Ortega y Fernando Guier Esquivel (†) la información sobre los doctores Angulo y Guier, respectivamente. A Raúl Arias Sánchez la fotografía de la casa que sirvió de hospital en Rivas, y a Antonio Vargas Campos (Museo Histórico Cultural Juan Santamaría) las figuras 1A, 1B, 3A, 3B, 5 y 6 . A Theresa White, la revisión del resumen en inglés. 
Revista Herencia, Vol. 34 (2), enero-junio, 2021.

\section{BIBLIOGRAFÍA}

Arias, R. (2002). Del Protomedicato al Colegio de Médicos y Cirujanos de Costa Rica; 145 años de historia. San José, Costa Rica: Editorial Porvenir.

Arias, R. (2007). Los soldados de la Campaña Nacional (1856-1857). Colección Biblioteca del Cincuenta y Seis, No. 2. EUNED. San José, Costa Rica.

Boletín Oficial de Costa Rica. Alcance. No. 179, 25-III-1856, p. 390.

Boletín Oficial de Costa Rica, No. 188, 30-IV-1856, p. 423-424.

Boletín Oficial de Costa Rica, No. 189, 3-V-1856, p. 428.

Boletín Oficial de Costa Rica, 14-V-1856, No. 192, p. 439 y 440.

Boletín Oficial de Costa Rica, 14-V-1856, No. 192, p. 441. 
Revista Herencia, Vol. 34 (2), enero-junio, 2021.

Fernández Guardia, R. (1980). Cosas y gentes de antaño. San José, Costa Rica: EUNED.

Hilje, L. (2007a). Karl Hoffmann, Cirujano Mayor del Ejército Expedicionario. Alajuela, Costa Rica: Editorial Colegio Universitario de Alajuela (CUNA).

Hilje, L. (2007b). Apuntes sobre los médicos extranjeros que participaron en la Campaña Nacional. Revista Electrónica de la Academia Costarricense de Ciencias Genealógicas 7, 57-66.

Hilje, L. (2010). La vida en San José a mediados del siglo XIX. Remembranzas de don Chico Rohrmoser. Revista Herencia, 23(2), 25-47.

Hilje, L. (2012). El obituario del Dr. Karl Hoffmann. Revista Comunicación, 21(1), 70-77.

Hilje, L. (2013). Trópico agreste; la huella de los naturalistas alemanes en la Costa Rica del siglo XIX. Cartago, Costa Rica: Editorial Tecnológica de Costa Rica. 
Revista Herencia, Vol. 34 (2), enero-junio, 2021.

Hilje, L. (2020). La bandera prusiana ondeó en Angostura. Instituto Costarricense de Electricidad.

Hilje, B. y M. Torres. (2018). La inmigración alemana a Costa Rica en el siglo XIX (18401900). Alajuela, Costa Rica: Editorial Universidad Técnica Nacional (EUTN).

Marr, W. (2002). Viajes por Centroamérica. En Ricardo Fernández Guardia (ed.). Costa Rica en el siglo XIX; relatos de viajeros (p. 95-210). San José, Costa Rica: EUNED.

Mata, L. (1992). El cólera: historia, prevención y control. San José, Costa Rica: Editorial Universidad de Costa Rica-EUNED.

Murchie, A.G. (1981). Imported spices: A study of Anglo-American settlers in Costa Rica, 1821-1900. San José, Costa Rica: Ministerio de Cultura, Juventud y Deportes.

Obregón, C. (Ed.). (2007). Diarios de Faustino Montes de Oca Gamero. San José, Costa Rica: Editorial de la Universidad de Costa Rica. 
Revista Herencia, Vol. 34 (2), enero-junio, 2021.

Obregón, R. (1991). Costa Rica y la guerra contra los filibusteros. Alajuela, Costa Rica: Museo Histórico Cultural Juan Santamaría.

Oconitrillo, E. (1998). El barrio Carit. En E. Oconitrillo y F.J. Enríquez (comp.). Historias de mi barrio: el San José de ayer (p. 231-243). San José, Costa Rica: Editorial Costa Rica.

Sáenz, A. (1940). Mis recuerdos de la batalla de Rivas. Revista de los Archivos Nacionales de Costa Rica 3-4, 215-216. 